\title{
Materials Research Express
}

\section{PAPER}

CrossMark

\section{Low temperature homogenization in nanocrystalline PdCu thin film system}

30 June 2015

PEVISED

27 August 2015

ACCEPTED FOR PUBLICATION

29 September 2015

PUBLISHED

DD MM 2015

\section{G Molnár ${ }^{1}$, G L Katona ${ }^{1}$, G A Langer ${ }^{1}$, A Csík ${ }^{2}$, Y C Chen $^{3}$ and D L Beke}

1 Department of Solid State Physics, University of Debrecen. PO Box 2. H-4010 Debrecen, Hungary

2 Nuclear Research Institute, Hungarian Academy of Sciences, H-4026 Debrecen, Bem sqr. 18c, Hungary

Institute of Electrical Engineering, Chinese Academy of Sciences, Beijing 100190, People's Republic of China

Keywords: diffusion, solid-state reaction, thin film, SNMS depth profile

\begin{abstract}
Abstact
Diffusion and solid state reactions were investigated in Pd-Cu nanocrystalline films by means of secondary neutral mass spectrometry depth profiling technique. The heat treatments were made at low temperatures (where the volume diffusion was frozen in) for long enough annealing times to reach saturation. In the early stage there is a grain boundary interdiffusion. At longer times first a Pd plateau developed inside the $\mathrm{Cu}$ layer. Later on the $\mathrm{Cu}$ penetration was also more and more extended in the $\mathrm{Pd}$, even the average composition of $\mathrm{Cu}$ in $\mathrm{Pd}$ became higher than the average $\mathrm{Pd}$ composition in $\mathrm{Cu}$. Depending on the ratio of the initial thicknesses, the system (for thickness ratios corresponding to $50 / 50 \mathrm{Cu} / \mathrm{Pd}$ or to $75 / 25 \mathrm{Cu} / \mathrm{Pd}$ ) arrived either at the mixture of pure $\mathrm{Pd}$ and $\beta$-CuPd phase or to the mixture of $\alpha^{\prime}-\mathrm{Cu}_{3} \mathrm{Pd}$ and $\beta$-CuPd phases, respectively, as dictated by the phase diagram. The process is interpreted as grain boundary diffusion induced solid state reaction.
\end{abstract}

\section{Introduction}

It is known that in thin layered systems homogenization can occur even at low temperatures where the volume diffusion can be neglected [1-4]. During these processes the interdiffusion takes place along grain-boundaries, GBs. The unequal GB atomic fluxes create stresses, the relaxation of which can result in (i) diffusion induced recrystallization (DIR) as well as (ii) in diffusion-induced grain boundary motion (DIGM). During DIR grains are created with a well-defined composition of the diffusing element. In DIGM the grain boundaries move perpendicular to the original boundary plane and leave an alloyed zone behind. Furthermore it was also illustrated [5-12] that complete homogenization of bilayered films can also happen by formations of reaction products along the grain boundaries, (grain boundary diffusion induced reaction, GBDIREAC [4]). The most important difference, as compared to the well-investigated cases of DIGM/DIR in systems forming solid solutions, lies in the formation of new phases. Nevertheless, in all these cases the nucleation and growth (either the nuclei formed in the vicinity of the original interface or formed along the GBs inside the film) are different from the normal planar nucleation and growth of the reaction product, when a compact reaction layer forms and grows at the original interface.

In our previous paper the interdiffusion in $\mathrm{Pd}-\mathrm{Cu}$ thin film system was investigated in the temperature range of $120^{\circ} \mathrm{C}-310^{\circ} \mathrm{C}[7]$. We have shown - in agreement with the experimental observations of [6] too- that the saturation of $\mathrm{GBs}$ in $\mathrm{Cu}$ was reached in very short times (in the early stages of the process), while we were able to determine the GB diffusion coefficient of $\mathrm{Cu}$ in Pd. In addition at $310^{\circ} \mathrm{C}$ after $1 \mathrm{~h}$ annealing time an almost complete homogenization with a composition of $\mathrm{Cu}_{3} \mathrm{Pd}$ was observed. The high concentration level of Pd in the center of the Cu layer, on the basis of TEM observations as well, was interpreted by moving GBs leaving behind regions of $\mathrm{Cu}_{3} \mathrm{Pd}$ composition. Since we did not detect the formation of a compact reaction layer near the original interface we interpreted our results by GBDIREAC.

In this paper we present systematic and detailed analysis of the later stages of phase formations with longterm heat treatments at low temperatures $\left(225^{\circ} \mathrm{C}-310{ }^{\circ} \mathrm{C}\right)$ in nanocrystalline $\mathrm{PdCu}$ system. 


\section{Experimental details}

Polycrystalline Pd/Cu bilayers were made on Si single crystalline substrate with dc magnetron sputtering. The pressure of the high purity Ar sputtering gas and the deposition rates of $\mathrm{Cu}$ and Pd were $5 \times 10^{-3} \mathrm{mbar}$, as well

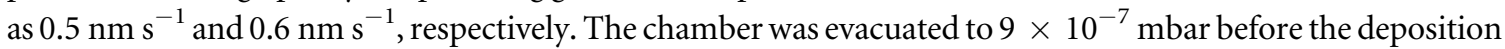
process to clear away every contamination. Films with thickness ratios corresponding to $\mathrm{Cu}: \mathrm{Pd}$ atomic ratios of 1:1 and 3:1 i.e. $37.5 \mathrm{~nm}(\mathrm{Pd}) / 30 \mathrm{~nm}(\mathrm{Cu})$ as well as $21 \mathrm{~nm}(\mathrm{Pd}) / 50 \mathrm{~nm}(\mathrm{Cu})$ films, respectively were produced. In addition, to change the thickness of the films, $62.5 \mathrm{~nm}(\mathrm{Pd}) / 50 \mathrm{~nm}(\mathrm{Cu})$ and $33.6 \mathrm{~nm}(\mathrm{Pd}) / 80 \mathrm{~nm}(\mathrm{Cu})$ bilyers were also deposited. The heat treatments were made in vacuum $\left(p<5 \times 10^{-6} \mathrm{mbar}\right)$ in the temperature range $180^{\circ} \mathrm{C}-280^{\circ} \mathrm{C}$. The concentration-depth profiles were measured by secondary neutral mass spectrometry (SNMS) technique where noble gas (Ar) plasma was used for sputtering and also for ionizing the sputtered neutral parts. The available best depth resolution is better than $2 \mathrm{~nm}[13,14]$ due to the extremely homogenous plasma profile and the low bombarding energy $(350 \mathrm{eV})$. From the intensity (count per second) versus sputtering time plots the concentration-depth profiles were calculated, using relative sensitivity factors and assuming linear relationship between the measured intensities and composition. The formed phases were also inspected by means of $\mathrm{x}$-ray diffraction (XRD) using $\mathrm{Cu} \mathrm{K} \alpha$ radiation in $\theta-2 \theta$ mode.

\section{Results}

Figures 1 and 2 show the time evolution of the concentration-depth profiles at $220^{\circ} \mathrm{C}$ for two different thickness ratios. One can see that first a Pd plateau developed inside the Cu layer at both thickness ratios and there is a gradual increase of the $\mathrm{Cu}$ composition in Pd closer to the initial interface. After longer annealing times there is a thin plateau at about 50/50 composition near the original interface in the $37.5 \mathrm{~nm}(\mathrm{Pd}) / 30 \mathrm{~nm}(\mathrm{Cu}$ ) bilayer (see figure $1(\mathrm{~d})$ ). In this diffusion couple the composition profiles gradually approached to each other at longer, prolonged aging (figure $1(\mathrm{f})$ ), indicating the homogenization with an average composition close to $50 \%$. In the bilayer with composition ratio 1:3,21 $\mathrm{nm}(\mathrm{Pd}) / 50 \mathrm{~nm}(\mathrm{Cu}$ ), the situation is similar on the Cu side (figure 2(b)), while in the Pd, probably due to the smaller Pd thickness, already after $12 \mathrm{~h}$ treatment a homogeneous layer with 50/50 composition has been developed (figure 2(c)). In addition, after more prolonged heat treatment, the composition on the $\mathrm{Cu}$ side started to approach to the composition corresponding to $\mathrm{Cu}_{3} \mathrm{Pd}$ (figure $2(\mathrm{~d})$ ) and at the same time the composition ratio on the original $\mathrm{Pd}$ side also gradually shifted from the CuPd content to more $\mathrm{Cu}$ rich compositions. In order to investigate the terminal state of both film ratios we also prepared thicker films corresponding to the same compositions with a bit increased individual thicknesses and heat treated them at higher temperature $\left(280^{\circ} \mathrm{C}\right.$, figure 3$)$. It can be seen from figures $3(\mathrm{~b})$ and (d) that again the systems approached to the expected $\mathrm{CuPd}$ and $\mathrm{Cu}_{3} \mathrm{Pd}$ final compositions, but obviously during much shorter times.

In contrast to our previous work [7], where only SNMS depth profiling was applied, XRD was also used to identify the growing phases. Figure 4 shows the XRD pattern of the $37.5 \mathrm{~nm}(\mathrm{Pd}) / 30 \mathrm{~nm}(\mathrm{Cu})$ film. The marked peaks of the XRD pattern were identified by the corresponding XRD patterns of $\mathrm{Cu}, \mathrm{Pd}$ and $\mathrm{CuPd}$ [6]. The silicon substrate has two reflections, at $69.1^{\circ}$ and $33^{\circ}$. The latter is related to enhanced stresses in the Si substrate [15]. XRD patterns of the as-deposited sample show the reflections of pure Pd and pure Cu only, which gradually decrease during the heat treatment. It can be seen that simultaneously with the decrease of the intensity of peaks for pure materials the reflections of the CuPd phase appear and grow (see (001), (110) and (112) reflections of this phase). Unfortunately the reflections of $\mathrm{Cu}(111)$ and $\mathrm{CuPd}(110)$ overlap at $43.3^{\circ}$. Figure 5 shows the XRD patterns of the $21 \mathrm{~nm}(\mathrm{Pd}) / 50 \mathrm{~nm}(\mathrm{Cu})$ film, corresponding to the 1:3 $\mathrm{Pd}$ :Cu ratio. The diffraction lines of the pure materials disappeared after $48 \mathrm{~h}$ long annealing. Reflections for the CuPd phase are observable, but the $\mathrm{Cu}_{3} \mathrm{Pd}$ phase cannot be identified.

XRD results on thicker samples (figure 6(a)) indicate that, as compared to figure 4, more reflections from the CuPd phase can be observed and the reflections from the pure $\mathrm{Cu}$ and Pd disappeared in the $62.5 \mathrm{~nm}(\mathrm{Pd}) /$ $50 \mathrm{~nm}(\mathrm{Cu})$ film, corresponding to the $1: 1 \mathrm{Cu} / \mathrm{Pd}$ ratio. On the other hand, as it can be seen in figure $6(\mathrm{~b})$ in the $33.6 \mathrm{~nm}(\mathrm{Pd}) / 80 \mathrm{~nm}(\mathrm{Cu})$ film with 3:1 Cu/Pd ratio, strong reflections from the $\mathrm{Cu}_{3} \mathrm{Pd}$ phase can be identified with some traces of reflections from the CuPd after $1 \mathrm{~h}$ heat treatment at $280{ }^{\circ} \mathrm{C}$.

Using the Scherrer formula [16], which is based on the line broadening of XRD peaks due to small grain size, $D$, the values of $D$ were estimated from the full-width at half-maximum of the XRD peaks (table 1 ). It can be seen from their comparison, although this method due to the instrumental line broadening inevitably underestimates the grain sizes, that probably because the grain structure is textured, the grain sizes estimated from different reflections are a bit different. On the other hand the grain sizes of the product and parent phases are the same within the errors of evaluation (about $2-3 \mathrm{~nm}$ ). 

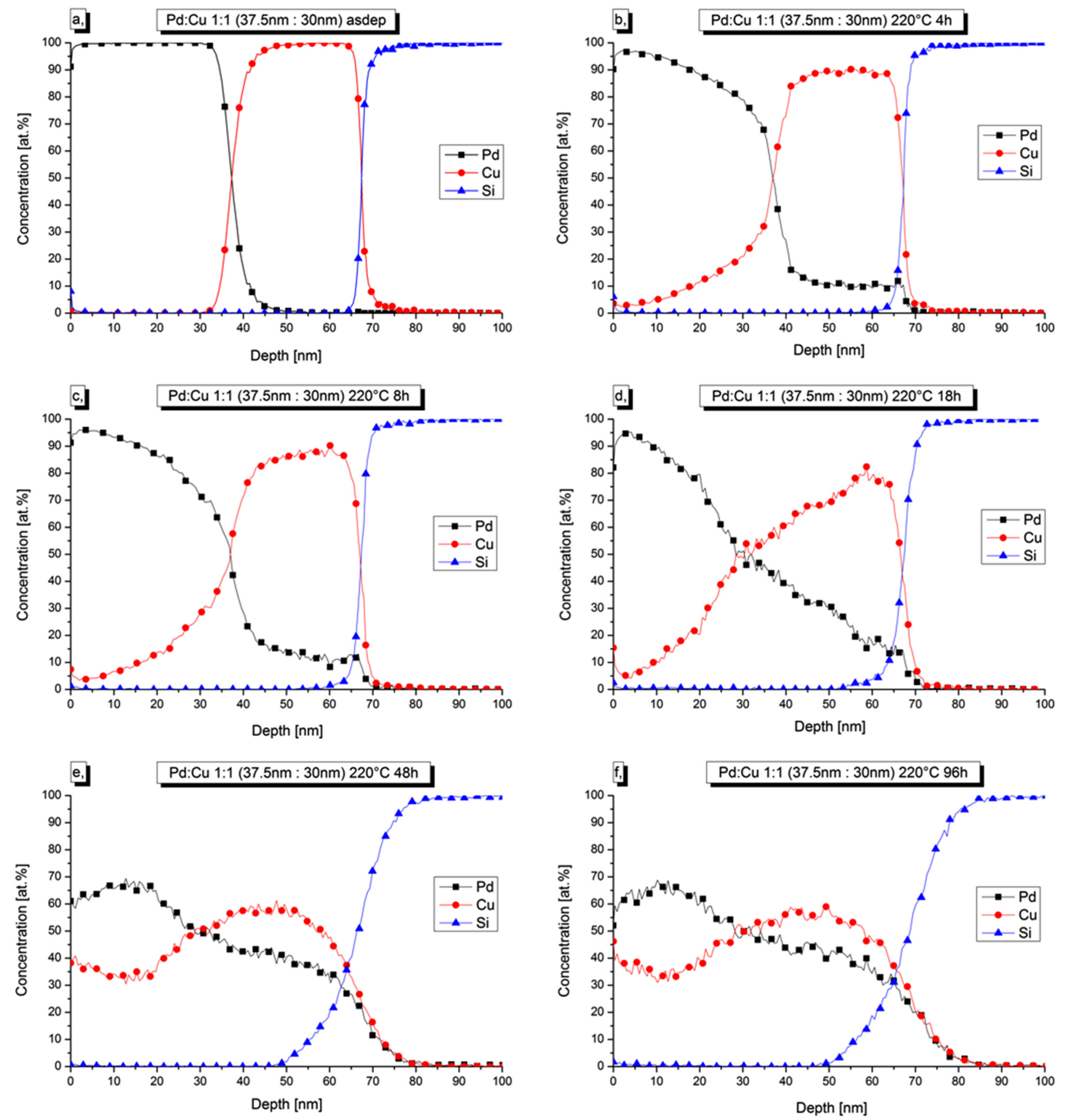

Figure 1. Concentration profiles in the $37.5(\mathrm{Pd}) / 30 \mathrm{~nm}(\mathrm{Cu})$ bilayer after different annealing times at $220^{\circ} \mathrm{C}$.

\section{Discussion}

We observed an almost full homogenization after long annealing times on the SNMS concentration-depth profiles (figures 1-3). The XRD measurements confirmed the conclusions drawn from the SNMS profiles: depending on the initial film thicknesses the system arrived either into the $\mathrm{CuPd}$ or $\mathrm{Cu}_{3} \mathrm{Pd}$ phases or to their mixture (see also below). Indeed, in accordance with the XRD results of [6] the phases, called CuPd as well as the $\mathrm{Cu}_{3} \mathrm{Pd}$ above, correspond to the $\beta(\mathrm{CuPd})$ and $\alpha^{\prime}\left(\mathrm{Cu}_{3} \mathrm{Pd}\right)$ phases with average equilibrium compositions 40 at $\%$ $\mathrm{Pd}$ as well as $15 \mathrm{at} \% \mathrm{Pd}$, respectively in accordance with the phase diagram [17]. Furthermore the presence of super-lattice reflections (with mixed, even and odd, indexes) indicates that the $\beta$ phase is at least partly ordered (figures 4 and 6(a)). Also, following the arguments in [6] it is likely, that the marked reflections $\left(\mathrm{Cu}_{3} \mathrm{Pd}\right)$ originate from the $\alpha^{\prime}-\mathrm{Cu}_{3} \mathrm{Pd}$ phase.

Since we did not observed (except the thin plateau at intermediate time in figure $1(\mathrm{~d})$ ) formation and planar growth of the reaction product at the initial interface, we offer the following interpretation. First the GB diffusion of atoms fills up the grain boundaries. Indeed, taking $0.5 \mathrm{~nm}$ for the grain-boundary width, the grainboundary volume fraction should be less than 12.5 at $\%$ for $d=12 \mathrm{~nm}(c \cong 3 \delta / d)$. The concentration of Pd in $\mathrm{Cu}$ is above this value after few hours. Later on the moving boundaries sweep through the grains and leave behind an alloyed zone as it is usually observed in DIGM: the mechanism of additional mass transfer to maintain the phase growth is the interface diffusion along the newly formed interfaces. In addition the alloyed zone 

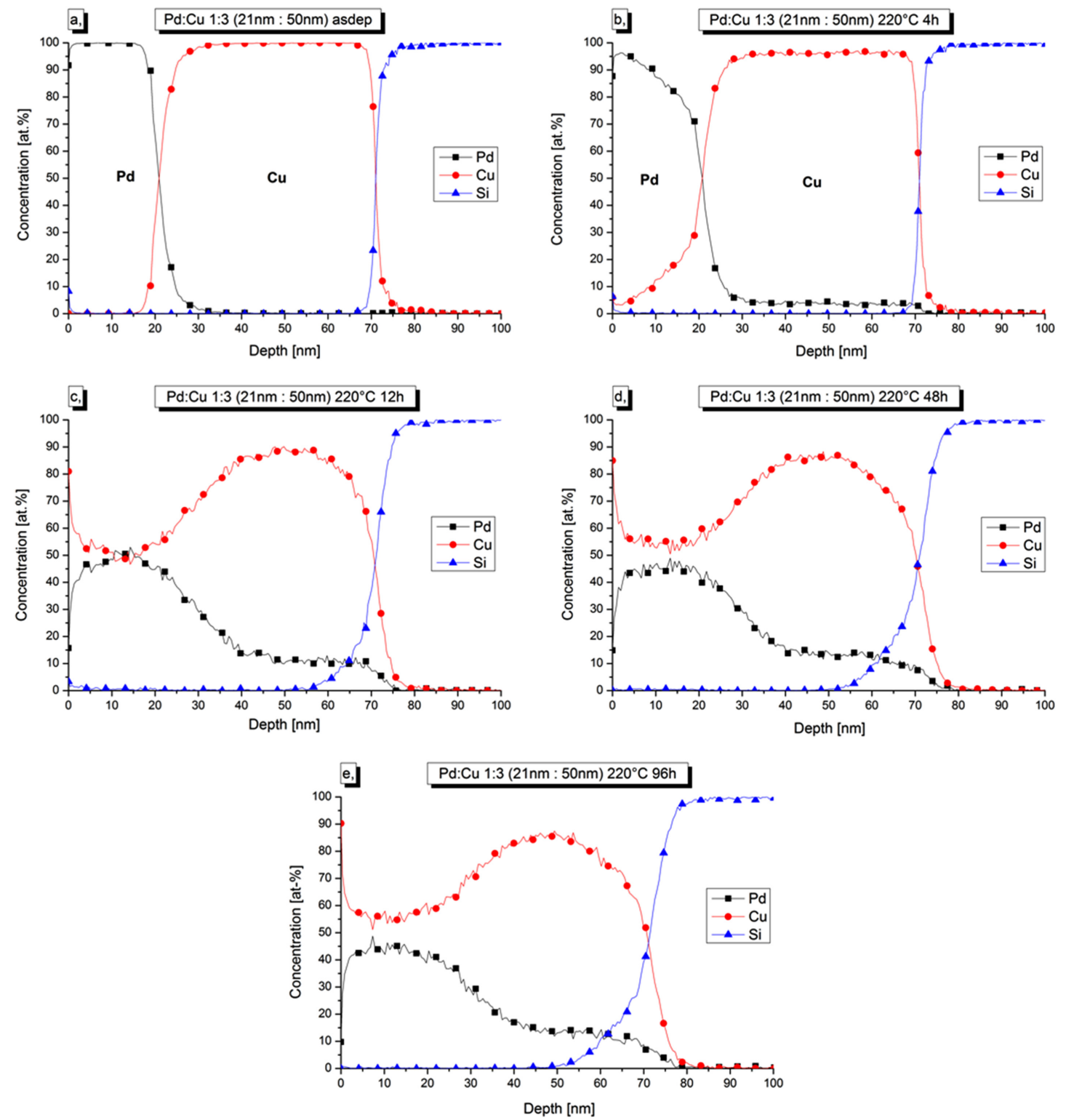

Figure 2. Concentration profiles in the $21 \mathrm{~nm}(\mathrm{Pd}) / 50 \mathrm{~nm}(\mathrm{Cu})$ bilayer after different annealing times at $220^{\circ} \mathrm{C}$.

consists of the intermetallic phase(s) formed by GBDIREAC. This is valid on both sides of all films investigated. The only difference is that, in the films with 1:3Pd/Cu ratio, this process if very profound on the Pd size, and almost all amount of Pd from the center of the Pd grains was consumed by this mechanism before the full homogenization reached. According to this explanation it is also clear why the composition profiles in figures 1(b)-(d) show some changes with the distance measured from the position of the original interface. The GBDIREAC process starts earlier at positions closer to the original interface and resulting in a gradual change in the depth profiles. At the vicinity of the original interface this can lead to a fast consumption of the interiors of the pure grains leading to the formation of the thin plato as it can be seen in figure 1 (d). Note that some contribution to the above processes from DIR can also play a role (see the discussion at the end of this section).

The fact that the system indeed arrived at thermal equilibrium in long time limit can also be illustrated by taking into account that in films with 50/50 initial $\mathrm{Cu} / \mathrm{Pd}$ ratio a mixture of pure $\mathrm{Pd}$ and the equilibrium $\beta$ phase (with 40 at $\% \mathrm{Pd}$ ) should be present with the overwhelming amount of the $\beta$ phase (the existence range of the $\beta$ phase is wide: it is about $10 \%$ ). Indeed it can be seen in figures $1(\mathrm{f})$ and $3(\mathrm{~b})$ that on the original $\mathrm{Cu}$ side the composition is about 40 at $\%$ of $\mathrm{Pd}$, while on the $\mathrm{Pd}$ side it exceeds the 60 at $\% \mathrm{Pd}$ indicating that in this side not all the Pd has been consumed and a mixture of the pure $\mathrm{Pd}$ and the (Pd rich) $\beta$ phase has been formed. This is accordance with the phase equilibrium: at 50/50 initial composition a mixture of the pure $\mathrm{Pd}$ and $\beta$ phase should be formed: this is why the average composition on the original Pd side is above the $60 \% \mathrm{Pd}(\mathrm{mixture}$ of $\mathrm{Pd}$ and $\beta$ phase) and it corresponds to the $\beta$ phase (with $40 \% \mathrm{Pd}$ ) on the $\mathrm{Cu}$ side. Indeed, as it can be seen in figures 4 

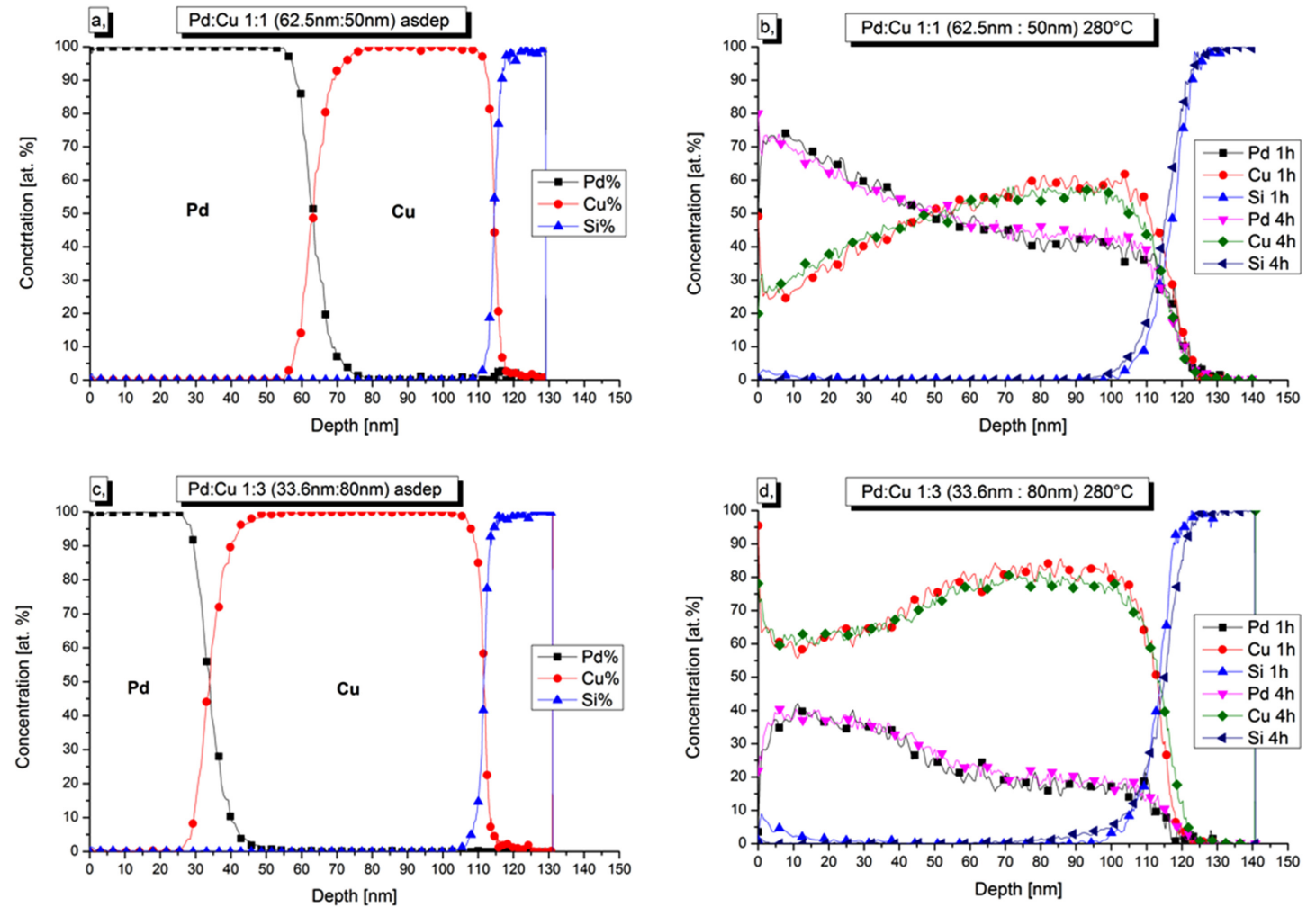

Figure 3. Concentration-depth profiles in $\mathrm{Pd} / \mathrm{Cu} 1: 1(62,5 \mathrm{~nm}: 50 \mathrm{~nm})$ and $\mathrm{Pd} / \mathrm{Cu}$ 1:3 (33.6 nm:80 nm) bilayers after deposition (a), 1 (b) and 4 (c) hours long annealing times at $280^{\circ} \mathrm{C}$.

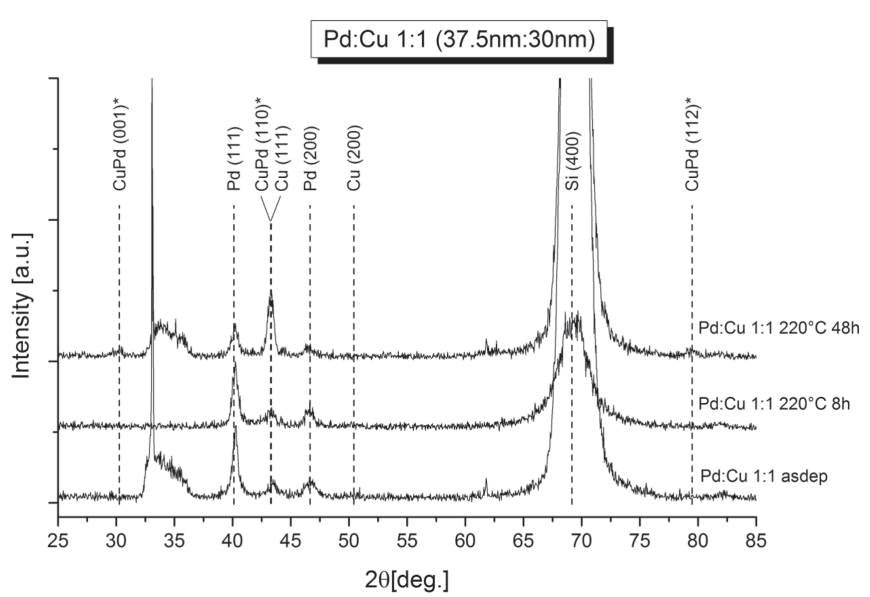

Figure 4. XRD spectra of the $\left(37.5(\mathrm{Pd}) / 30 \mathrm{~nm}(\mathrm{Cu})\right.$ thin film after different annealing times at $220{ }^{\circ} \mathrm{C}$. Peaks belonging to super-lattice reflections are denoted by*

and 6(a), only the reflections from the Pd and the CuPd are present after the heat treatments. Similarly in films with 75/25 initial Cu/Pd ratio the mixture of the $\alpha^{\prime}$ and $\beta$ phases should be present. As it can be seen from figures 2(e) and 3(d) this is the case after longer annealing times: the composition is about 40 at $\% \mathrm{Pd}$ on the Pd side ( $\beta$ phase) and about $15 \%$ on the $\mathrm{Cu}$ side ( $\alpha^{\prime}$ phase). This is also supported by the XRD result shown in figures 5 and 6(b): there are no peaks from $\mathrm{Cu}$ and $\mathrm{Pd}$ and only reflections from the $\beta$ and $\alpha^{\prime}$ phases are present. There is one more argument supporting that the system reached the thermal equilibrium in both of the above two cases. While the time evolution of the composition profiles was quite fast in the first parts of the heat treatments, there are almost no changes in figures 3(b) and (d) between $1 \mathrm{~h}$ and $4 \mathrm{~h}$ heat treatments, indicating that the system has reached the equilibrium already after $1 \mathrm{~h}$.

The contribution from diffusion induced re-crystallization, DIR, can not be fully excluded on the basis of our present results only. First, similarly as it was observed in some thin film reactions with nanocrystalline 


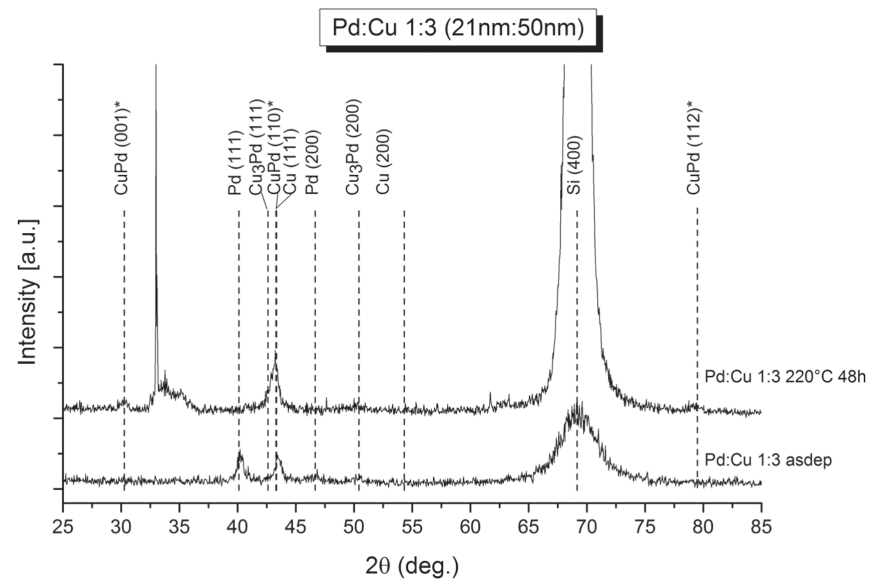

Figure 5. XRD spectra of the $21 \mathrm{~nm}(\mathrm{Pd}) / 50 \mathrm{~nm}(\mathrm{Cu})$ thin film in the as deposited state and after $48 \mathrm{~h}$ annealing time at $220{ }^{\circ} \mathrm{C}$. Peaks belonging to super-lattice reflections are denoted by*.
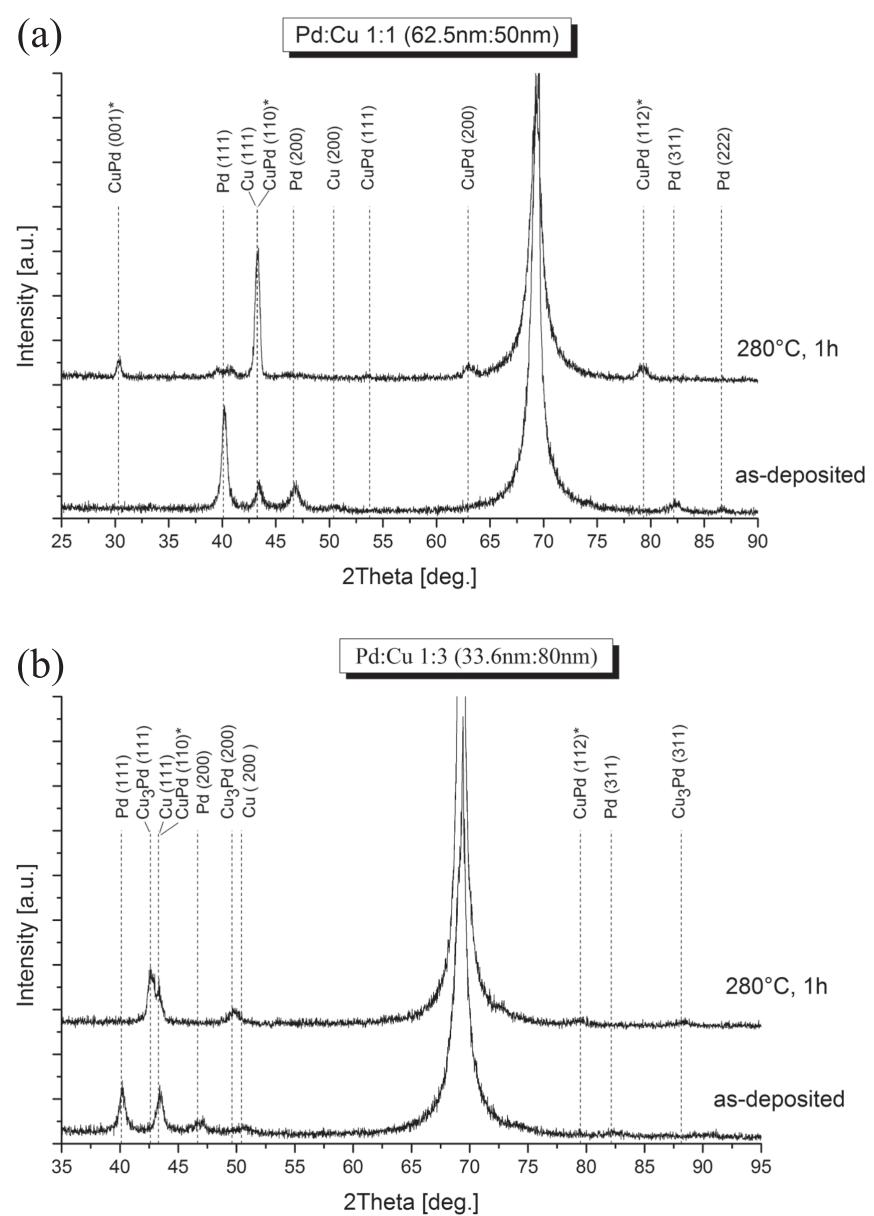

Figure 6. XRD patterns of the Pd:Cu 1:1 (62.5 nm:50 nm) (a) and Pd:Cu 1:3 (33.6 nm:80 nm) (b) thin films after $1 \mathrm{~h}$ annealing time at $280{ }^{\circ} \mathrm{C}$. Peaks belonging to super-lattice reflections are denoted by*.

structures [5, 18], DIR, could produce new grains and their growth and subsequent nucleation at the moving interfaces could lead to a similar increase of the amount of the reaction product as observed. Second, the observation of the transient thin planar phase in figure $1(\mathrm{~d})$, can also be a result of nucleation of the new phase at the intersection of the GBs with the initial interface and their subsequent growth could lead the formation of a continuous planar layer. On the other hand the grain sizes of the new phases did not considerably differ from the 
Table 1. Grain sizes as calculated from XRD patterns.

\begin{tabular}{|c|c|c|c|}
\hline Sample & Heat treatement & Peak & Grain size $D(\mathrm{~nm})$ \\
\hline $\mathrm{Pd}: \mathrm{Cu}(37,5 \mathrm{~nm} / 30 \mathrm{~nm})($ figure 4$)$ & as-deposited & $\operatorname{Pd}(111)$ & 17 \\
\hline Pd:Cu (37,5 nm/30 nm) (figure 4) & as-deposited & $\operatorname{Pd}(200)$ & 7 \\
\hline Pd:Cu (37,5 nm/30 nm) (figure 4) & as-deposited & $\mathrm{Cu}(111)$ & 11 \\
\hline $\mathrm{Pd}: \mathrm{Cu}(37,5 \mathrm{~nm} / 30 \mathrm{~nm})($ figure 4$)$ & $220^{\circ} \mathrm{C}, 48 \mathrm{~h}$ & $\operatorname{Pd}(111)$ & 11 \\
\hline Pd:Cu (37,5 nm/30 nm) (figure 4) & $220^{\circ} \mathrm{C}, 48 \mathrm{~h}$ & $\operatorname{Pd}(200)$ & 10 \\
\hline Pd:Cu (37,5 nm/30 nm) (figure 4) & $220^{\circ} \mathrm{C}, 48 \mathrm{~h}$ & $\operatorname{CuPd}(110)$ & 14 \\
\hline Pd:Cu (37,5 nm/30 nm) (figure 4) & $220^{\circ} \mathrm{C}, 48 \mathrm{~h}$ & $\mathrm{CuPd}(001)$ & 6 \\
\hline $\mathrm{Pd}: \mathrm{Cu}(21 \mathrm{~nm} / 50 \mathrm{~nm})$ (figure 5) & as-deposited & $\operatorname{Pd}(111)$ & 14 \\
\hline $\mathrm{Pd}: \mathrm{Cu}(21 \mathrm{~nm} / 50 \mathrm{~nm})($ figure 5) & as-deposited & $\operatorname{Pd}(200)$ & 7 \\
\hline $\mathrm{Pd}: \mathrm{Cu}(21 \mathrm{~nm} / 50 \mathrm{~nm})($ figure 5) & as-deposited & $\mathrm{Cu}(111)$ & 14 \\
\hline $\mathrm{Pd}: \mathrm{Cu}(21 \mathrm{~nm} / 50 \mathrm{~nm})($ figure 5) & $220^{\circ} \mathrm{C}, 48 \mathrm{~h}$ & $\operatorname{CuPd}(110)$ & 11 \\
\hline Pd:Cu (21 nm/50 nm) (figure 5) & $220^{\circ} \mathrm{C}, 48 \mathrm{~h}$ & $\operatorname{CuPd}(001)$ & 13 \\
\hline $\mathrm{Pd}: \mathrm{Cu}(62,5 \mathrm{~nm} / 50 \mathrm{~nm})($ figure $6(\mathrm{a}))$ & as-deposited & $\operatorname{Pd}(111)$ & 15 \\
\hline $\mathrm{Pd}: \mathrm{Cu}(62,5 \mathrm{~nm} / 50 \mathrm{~nm})($ figure $6(\mathrm{a}))$ & as-deposited & $\operatorname{Pd}(200)$ & 9 \\
\hline $\mathrm{Pd}: \mathrm{Cu}(62,5 \mathrm{~nm} / 50 \mathrm{~nm})($ figure $6(\mathrm{a}))$ & as-deposited & $\mathrm{Cu}(111)$ & 13 \\
\hline Pd:Cu $(62,5 \mathrm{~nm} / 50 \mathrm{~nm})($ figure $6(\mathrm{a}))$ & $280^{\circ} \mathrm{C}, 1 \mathrm{~h}$ & $\operatorname{CuPd}(001)$ & 18 \\
\hline Pd:Cu $(62,5 \mathrm{~nm} / 50 \mathrm{~nm})($ figure $6(\mathrm{a}))$ & $280{ }^{\circ} \mathrm{C}, 1 \mathrm{~h}$ & $\operatorname{CuPd}(110)$ & 17 \\
\hline $\mathrm{Pd}: \mathrm{Cu}(33,6 \mathrm{~nm} / 80 \mathrm{~nm})($ figure 6(b)) & as-deposited & $\operatorname{Pd}(111)$ & 14 \\
\hline $\mathrm{Pd}: \mathrm{Cu}(33,6 \mathrm{~nm} / 80 \mathrm{~nm})$ (figure 6(b)) & as-deposited & $\operatorname{Pd}(200)$ & 6 \\
\hline $\mathrm{Pd}: \mathrm{Cu}(33,6 \mathrm{~nm} / 80 \mathrm{~nm})($ figure 6(b)) & as-deposited & $\mathrm{Cu}(111)$ & 13 \\
\hline $\mathrm{Pd}: \mathrm{Cu}(33,6 \mathrm{~nm} / 80 \mathrm{~nm})($ figure $6(\mathrm{~b}))$ & $280{ }^{\circ} \mathrm{C}, 1 \mathrm{~h}$ & $\operatorname{CuPd}(110)$ & 14 \\
\hline $\mathrm{Pd}: \mathrm{Cu}(33,6 \mathrm{~nm} / 80 \mathrm{~nm})($ figure $6(\mathrm{~b}))$ & $280{ }^{\circ} \mathrm{C}, 1 \mathrm{~h}$ & $\mathrm{Cu}_{3} \mathrm{Pd}(111)$ & 14 \\
\hline $\mathrm{Pd}: \mathrm{Cu}(33,6 \mathrm{~nm} / 80 \mathrm{~nm})($ figure $6(\mathrm{~b}))$ & $280^{\circ} \mathrm{C}, 1 \mathrm{~h}$ & $\mathrm{Cu}_{3} \mathrm{Pd}(200)$ & 9 \\
\hline
\end{tabular}

initial values of the parent films (table 1). Since after the nucleation of new grains by DIR some recrystallization can take place, further microscopic investigation would be necessary to explore the details.

\section{Conclusions}

We have shown that the intermixing between the $\mathrm{Cu}$ and $\mathrm{Pd}$ thin films takes place by grain-boundary/interface diffusion leading to phase formation along the grain-boundaries. During this process the new phases grow by the motion of newly formed interfaces. The system arrived either at the mixture of pure $\mathrm{Pd}$ and $\beta$-CuPd phase or to the mixture of $\alpha^{\prime}-\mathrm{Cu}_{3} \mathrm{Pd}$ and $\beta$-CuPd phases, when the initial thickness ratio corresponded to $50 / 50 \mathrm{Cu} / \mathrm{Pd}$ or to $75 / 25 \mathrm{Cu} / \mathrm{Pd}$, respectively. Furthermore, XRD results showed that the $\beta$ phase was at least partially ordered.

\section{Acknowledgments}

This work was supported by TÁMOP 4.2.2/B-15/1/KONV-2015-0001 as well as by the TÁMOP 4.2.4. A/2-111-2012-0001 'National Excellence Program' (author G L Katona) projects, which is implemented through the New Hungary Development Plan co-financed by the European Social Fund and the European Regional Development Fund. Support from the Hungarian-Chinese bilateral project, TÉT_12_CN-1-2012-0036, is also acknowledged. This work has been also supported by the OTKA (Hungarian Scientific Research Fund) project NF 101329.

\section{References}

[1] Schmitz G, Baither D, Kasprzak M, Kim T H and Kruse B 2010 The hidden link between diffusion-induced recrystallization and ideal strength of metals Scr. Mater. 63 484-7

[2] Kosevich V M, Gladkikh A N, Karpovskyi M V and Klimenko V N 1995 Interdiffusion in two-layer Pd/Ag films: II. 'Cold' homogenization mechanisms Interface Sci. 2

[3] Paritskaya L N, Kaganovskii Y and Bogdanov V V 2005 Size-dependent interdiffusion in nanomaterials Solid State Phenom. 123-30 (http://scientific.net/SSP.101-102.123)(accessed 17 June 2015)

[4] Beke D L et al 2012 Kinetic pathways of diffusion and solid-state reactions in nanostructured thin films Philos. Mag. 1-11

[5] Shenouda S S, Langer G A, Katona G L, Daróczi L, Csik A and Beke D L 2014 Production of NiSi phase by grain boundary diffusion induced solid state reaction between $\mathrm{Ni2Si}$ and Si(100) substrate Appl. Surf. Sci. 320 627-33

[6] Chakraborty J, Welzel U and Mittemeijer E J 2008 Interdiffusion, phase formation, and stress development in Cu-Pd thin-film diffusion couples: interface thermodynamics and mechanisms J. Appl. Phys. 103 1-15

[7] Molnár G et al 2013 Evolution of concentration profiles in Pd-Cu systems studied by SNMS technique Vacuum 98 70-4 
[8] Hartung F and Schmitz G 2001 Interdiffusion and reaction of metals: the influence and relaxation of mismatch-induced stress Phys. Rev. B 64245418

[9] Tynkova A, Katona G L, Langer G A, Sidorenko S I, Voloshko S M and Beke D L 2014 Formation of Cu $\mathrm{Au}_{1-x}$ phases by cold homogenization of Au/Cu nanocrystalline thin films Beilstein J. Nanotechnology 5 1491-500

[10] Katona G L et al 2013 Grain boundary diffusion induced reaction layer formation in Fe/Pt thin films Appl. Phys. A 115 203-11

[11] Beke D L, Erdélyi Z and Katona G L 2014 Anomalous kinetics and regimes of growth of intermetallic phases during solid state reactions in nanosystems Diffus. Found. 107-39 (http://scientific.net/DF.2.107) (accessed 17 June 2015)

[12] Pan J D and Balluffi R W 1982 Diffusion induced grain boundary migration in and thin films Acta Metall. 30 861-70

[13] Oechsner H 1993 Recent instrumental developments in surface and thin-film analysis by electron and mass spectrometric techniques Appl. Surf. Sci. 70-71 250-60

[14] Jorzick J, Lösch J, Kopnarski M and Oechsner H 2004 Detection in the ppm range and high-resolution depth profiling with the new SNMS instrument INA-X Appl. Phys. A 78 655-8

[15] Hwang B-H 2001 Calculation and measurement of all (002) multiple diffraction peaks from a (001) silicon wafer J. Phys. D: Appl. Phys. 342469-74

[16] Patterson A 1939 The scherrer formula for x-ray particle size determination Phys. Rev. 56 978-82

[17] Massalski T B and Okamoto H 1990 Binary Alloy Phase Diagrams (ASM International) pp 1454-6

[18] Sobiech M, Krüger C, Welzel U, Wang J-Y, Mittemeijer E J and Hügel W 2011 Phase formation at the Sn/Cu interface during room temperature aging: microstructural evolution, whiskering, and interface thermodynamics J. Mater. Res. $261482-93$ 


\section{QUERY FORM}

\section{JOURNAL: Materials Research Express}

Author: G Molnár et al

TitLE: Low temperature homogenization in nanocrystalline $\mathrm{PdCu}$ thin film system

ARTIClE ID: mrxaa0512

The layout of this article has not yet been finalized. Therefore this proof may contain columns that are not fully balanced/matched or overlapping text in inline equations; these issues will be resolved once the final corrections have been incorporated.

We have been provided funding information for this article as below. Please confirm whether this information is correct. TÁMOP: 4.2.2/B-15/1/KONV-2015-0001, 4.2.4. A/2-11-1-2012-0001; Hungarian-Chinese bilateral project, TÉT:_12_CN-1-2012-0036; OTKA (Hungarian Scientific Research Fund): NF 10132.

Page 1

Q1

Please specify the corresponding author and provide his/her email address.

Page 7

Q2

Please check the details for any journal references that do not have a link as they may contain some incorrect information.

Page 7

Q3

Please provide page range/article number details for reference [2].

Page 7

Q4

Please provide the volume for references $[3,4,11]$.

Page 8

Q5

Publisher location and name are required for book references 17]. Please provide the missing information. 